\title{
A IMPORTÂNCIA DA DIGITALIZAÇÃO DE DOCUMENTOS PARA A EFICIÊNCIA DAS ORGANIZAÇÕES
}

\author{
Alessandra Harumi Sakai dos Santos, Josélia Galiciano Pedro \\ Universidade Oeste Paulista, Curso de Administração, Presidente Prudente, SP. E-mail: alessandra.sakai@hotmail.com
}

\begin{abstract}
RESUMO
Hodiernamente as ferramentas tecnológicas tem sido uma grande auxiliadora nos processos empresariais, proporcionando mudanças significativas em suas operações. Em busca de eficiência e agilidade o sistema de gerenciamento de informação, é uma alternativa que por meio da digitalização de documentos poderá minimizar o excesso de papel, bem como suprimir perdas de documentos. O objetivo deste estudo foi sopesar a ferramenta de digitalização de documentos nos processos administrativos para auxiliar no gerenciamento dos processos empresariais. A metodologia constou de pesquisa bibliográfica, por meio de uma abordagem qualitativa. Os resultados obtidos mostraram a importância da implementação de um sistema de digitalização de documentos, o qual proporciona agilidade e acessibilidade para a organização no todo. Concluímos que a digitalização é fundamental para as empresas na parte de eficiência e agilidade das operações para o atingimento de resultados.
\end{abstract}

Palavras-chave: Digitalização. Sistema de Informação Gerencial. Eficiência.

\section{THE IMPORTANCE OF SCANNING DOCUMENTS TO THE EFFICIENCY OF ORGANIZATIONS}

\begin{abstract}
Technological tools in our times has been a great helper in business processes, providing significant changes in its operations. In search of efficiency and agility the information management system, it is an alternative that through document scanning can minimize the excess paper to abolish document losses. The objective of this study was to weigh the document scanning tool in the administrative processes to help manage business processes. The methodology consisted of bibliographical research, through a qualitative approach. The results showed the importance of implementing a document scanning system, which provides agility and accessibility to the organization on the whole. We conclude that the scanning is critical for companies on the efficiency and agility of operations for the achievement of results.
\end{abstract}

Keywords: Scanning, Management Information System. efficiency 
Com a evolução da internet e de novas ferramentas de gestão virtual, os administradores podem atingir resultados satisfatórios em seus processos organizacionais, promovendo agilidade e eficiência no atendimento ao público. Medidas de modernização vêm sendo aplicadas pelas organizações privadas e públicas. Posto que, as empresas estatais não apresentem como objetivo principal a lucratividade, a utilização de métodos de gestão virtual e de informações realizados de forma adequada pode tornar os processos empresariais mais eficientes, evitando o retrabalho e otimizando o tempo.

O sistema de informação Gerenciais, é uma ferramenta importante neste processo de digitalização. Oliveira (2002, p. 65), apresenta o significado de SIG: “[...] é o processo de transformação de dados em informações, que são utilizadas na estrutura decisória da empresa como ferramenta que possibilita a sustentação administrativa para otimizar os resultados esperados."

O SIG é uma tecnologia que fornece informações precisas às operações internas, promovendo uma boa continuidade da empresa. Verifica a informação no momento certo, oferecendo relatórios de prontidão para a tomada de decisão.

Diante do exposto, esta pesquisa versa sobre o objetivo de sopesar a ferramenta de digitalização de documentos nos processos administrativos para auxiliar no gerenciamento dos processos empresariais.

\section{METODOLOGIA}

O caminho a ser percorrido é de extrema importância, já que orienta os meios para se atingir os resultados esperados.

O ajustamento do método é assaz para o bom andamento da pesquisa, já que estará moldada para percorrer caminhos preestabelecidos e acentuados. (OLIVEIRA, 1999). Confere que a metodologia é composta por vários métodos que combinados formam um processo, que visa guiar para a discussão das premissas básicas do estudo, baseados em regras e procedimentos científicos.

Portanto, em consideração aos objetivos da pesquisa, esta, foi pautada na abordagem qualitativa, constou de pesquisa bibliográfica, pois almejou entender alguns termos e demonstrou a melhor maneira de melhorar os processos administrativos.

\section{RESULTADOS}


As evidências disponíveis demonstram que a digitalização traz eficiência e agilidade nos processos organizacionais, além de proporcionar a computação verde, eliminando assim o excesso de papelório. As informações ficam disponíveis em tempo real, o que agiliza a tomada de decisão. Para o administrador essa ferramenta, conforme pesquisa, traz benefícios como a organização dos documentos, através da digitalização dos mesmos.

\section{DISCUSSÃO}

A tecnologia da informação tem influência direta na atuação das empresas, que por sua vez, engendram mecanismos de atualização para atingir um patamar aceitável, e de superação a essas novas situações. O ritmo da mudança está cada vez mais frenético e as pessoas precisam reagir mais velozmente, sendo proativas em seus atos e não habituar-se ao comodismo.

"A atividade empresarial mais importante da atualidade consiste em conceber e desenvolver mudanças em grandes escalas, a fim de melhorar o nível de rendimentos". (JÚLIO; SALIBE NETO, 2001, p. 28). Essas mudanças conforme os autores são importantes para se obter bons resultados, porém deve se ter alguns cuidados na sua implementação, principalmente quando a empresa está excessivamente burocratizada e adormecida.

De acordo com Ghoshal (apud JÚLIO; SALIBI NETO, 2001, p. 51)

Não é possível, claro, transformar uma organização sem revitalizar seus funcionários; é preciso influir em seu comportamento e em sua maneira de pensar. Mas não é esse o grande desafio. É preciso, isto sim, deixar as pessoas trabalharem em condições favoráveis e que atendam as "sugestões" feitas pelo ambiente. É por essa razão que o primeiro e verdadeiro desafio é criar um ambiente próprio para cada organização.

Para fomentar uma transformação em uma organização, o autor ressalta que a conscientização do porquê dessa mudança é fundamental, já que o novo suscita indagações, que deverão ser sanadas antes mesmo de sua introdução. Mas o grande desafio está na criação de um ambiente próprio para cada organização, pois as mesmas possuem características que diferem umas das outras, como exemplo pode-se citar uma empresa burocrática, que segundo Marcovitch (2007), essas empresas possuem gargalos que inibem a eficiência dos projetos do executivo, isso se dá desde os métodos obsoletos da administração que resistiram ao longo do tempo e deixaram traços no País.

Para o autor essas empresas possuem regras que são importantes, no entanto, precisarão ser adequadas ao contexto existente. Se o ambiente em que está inserido exige certa agilidade e 
os recursos estão disponíveis, faz-se necessário uma rápida adequação para cada tipo de organização.

Atualmente o uso da tecnologia e dos sistemas de informação tem aumentado gradativamente, isso se dá devido as exigências do mercado em que estamos inseridos.

Laudon e Laudon (2007, p. 6), destacam:

As empresas estão sempre tentando melhorar a eficiência em suas operações a fim de conseguir maior lucratividade. Das ferramentas que os administradores dispõem, as tecnologias e o sistema de informação estão entre as mais importantes para atingir os níveis de eficiência e produtividade nas operações, especialmente quando combinados com mudanças no comportamento da organização e das práticas do negócio.

A colocação dos autores vem corroborar a importância de se utilizar as ferramentas que auxiliam no processo de tomada de decisão. Para compreender claramente o uso dessas ferramentas, se faz necessário a definição das mesmas.

Oliveira (2010, p. 24, grifo do autor) define que "Sistema é o conjunto de partes interagentes e interdependentes que, conjuntamente, formam um todo unitário com determinado objetivo e efetuando uma função." Por conseguinte, entende -se que um sistema é um processo organizado e dinâmico com as funções de entrada, processamento e saída que interage com o ambiente.

O' Brien (2004, p. 13, grifo do autor) conceitua a "informação como dados que foram convertidos em um contexto significativo e útil para usuários finais específicos". De tal modo, percebe-se que a informação é um produto concluído, ou seja, resultado de uma análise organizada e manipulada de um conjunto de dados.

Como dito anteriormente, os recursos de dados são recebidos por um sistema que processa e gera informação, sendo assim, um Sistema de Informação (SI) é um conjunto organizado de pessoas, software, hardware, redes de comunicação e recursos de dados que coleta, transforma e dissemina informações em uma organização, (O' BRIEN, 2004). Evidencia-se, portanto, que conhecer os sistemas de informação é importante porque esses darão apoio as operações empresariais, à tomada de decisão e à vantagem competitiva, o qual incluem o sistema de Apoio às Operações (SAO) ${ }^{1}$ e Sistema de Apoio Gerencial (SAG) ${ }^{2}$.

\footnotetext{
${ }^{1}$ SAO - Processa transações eficientemente, controla processos, apoia comunicações e colaborações e faz a atualização de banco de dados.

${ }^{2}$ SAG - Fornece informação e apoio aos gerentes na tomada de decisão eficaz. 
Oliveira (2002, p. 65), explica o significado de SIG: “[...] é o processo de transformação de dados em informações, que são utilizadas na estrutura decisória da empresa como ferramenta que possibilita a sustentação administrativa para otimizar os resultados esperados."

Sendo assim, o SIG é uma tecnologia que fornece informações às operações internas e sobre o ambiente, o que facilita a tomada de decisão.

Segundo Stair e Reynolds (2002, p. 19):

Os sistemas de informação gerenciais, desenvolvidos inicialmente na década 60, eram caracterizados pelo uso de sistemas de informação para produzir relatórios gerenciais. Na maioria dos casos, esses primeiros relatórios eram produzidos periodicamente [...]. Como eram impressos regularmente, foram denominados relatórios programados, os quais ajudavam os gerentes a executar suas obrigações.

Observa-se então, que o Sistema de Informação Gerenciais (SIG) auxilia o processo decisório da empresa tornando os processos mais eficientes e as decisões mais precisas.

A eficiência é, portanto, o objetivo principal da implantação de um SIG. Para Moraes (2010, p. 73):

A eficiência refere-se à relação entre os resultados obtidos e os recursos empregados. Existem diversos tipos de eficiência, que se aplicam a áreas diferentes do conhecimento. A eficiência representa uma medida segundo o qual os recursos são convertidos em resultados de forma mais econômica.

Nota-se que o autor, demonstra ênfase a eficiência, onde através da mesma se atinge os resultados economicamente. Pode-se considerar a importância do gerenciamento da informação para obter uma base sólida para as decisões e processos operacionais, alcançando assim resultados satisfatórios.

“Empresas, indivíduos e governos deverão incorporar os avanços tecnológicos a suas respectivas realidades se ainda não o fizeram. A eficiência máxima depende da capacidade de interconexão", (OLIVEIRA, 2003, p. 225).

Conforme a colocação do autor, a eficiência será alcançada quando a informação for acessível a todos os tomadores de decisão, de forma dinâmica.

Nogas, Luz e Navarro (apud LUZ, 2011, p. 35) afirmam o seguinte:

O valor da informação está associado ao seu uso final, ou seja, sua utilidade efetiva, onde dentro de um contexto possa ser relacionada e interpretada para transmitir conhecimento e permitir que a tomada de decisão seja otimizada [...]. Deve ter a capacidade de reduzir incertezas no momento da efetiva decisão, nem antes, nem depois. 
As informações são de extrema importância, por isso o autor coloca que o seu valor está associado ao seu uso final. A informação bem trabalhada pode gerar acertos na tomada de decisão.

Oliveira (2010) destaca a dificuldade que as empresas têm em avaliar e mensurar os benefícios da aplicação de um SIG, o levantamento de algumas hipóteses como redução dos custos de operações, aumento da produtividade e melhoria nos fluxos de informações e no processo administrativo podem ajudar à entende-los, ainda que de forma generalista.

Para que tudo isso seja realizado de forma eficiente, faz se necessário a digitalização de documentos. Esta é realizada por meio de escâner.

Avedon (1999, p. 184) explica de forma geral que a digitalização é o "uso de um escâner para converter documentos (em papel ou microfilmes) em imagens eletrônicas codificadas digitalmente e que são apropriadas para armazenamento magnético ou óptico." Entende-se que a digitalização é a transformação real de algo tangível em intangível, sendo visualizada por meio eletrônico.

O arquivo gerado eletronicamente necessita ser gerenciado, para que seja localizado facilmente com um clique, e o autor salienta a importância do Gerenciamento Eletrônico de Documentos (GED) que é um dos requisitos para o bom resultado da digitalização. O GED é o "Uso coordenado de todas as técnicas de captura, gravação, processamento, armazenamento, transferência e uso de imagens" (AVEDON, 1999, p. 189). Portanto, o GED trata e processa automaticamente documentos de papel em computadores, pois quando estes são captados assumem o formato do documento original, até mesmo um contrato ou documento com firma reconhecida e sua respectiva assinatura.

Para que o GED seja operado, necessita de um Sistema de Gerenciamento de Documentos (SGD), onde Turban e Volonino (2013, p. 68) esclarecem que esse sistema:

[...] consistem em hardware e software que geram e arquivam documentos eletrônicos, indexando-os e organizando de acordo com as políticas da empresa. [...] Esses sistemas minimizam as ineficiências e as frustrações associadas ao gerenciamento de documentos em papel ou fluxo de trabalho com papeis.

O trabalho conjunto dessas ferramentas trará resultados em segundos pois facilitará a busca do documento virtual, tornando as operações internas mais eficientes e oferecendo uma prestação de serviços mais ágeis. O SGD pode ajudar uma organização a se tornar mais eficiente e produtiva: 
- Permitindo que a empresa acesse e use o conteúdo encontrado em documentos

- Cortando custos de trabalho pela automatização de processos de negócios

- Reduzindo o esforço e o tempo requeridos para localizar informações de que o negócio precisa para dar suporte a tomada de decisão

- Melhorando a segurança do conteúdo, reduzindo dessa forma o risco de roubo de propriedade intelectual

- Minimizando os custos associados a impressão, armazenamento e busca de conteúdo. (TURBAN E VOLONINO, 2013, p. 68)

Conforme os cinco itens alocados, tem-se que a utilização do SGD pode promover um grande desenvolvimento na empresa no sentido de melhoria nos processos e nos custos operacionais. Os mesmos autores trazem que além do aumento da produtividade e da diminuição dos custos, as obrigações impostas são mais fáceis de verificar e a computação verde se torna possível, quando o fluxo de trabalho é digital. Diversos fatores levam a necessidade dessa implementação, pois as pessoas precisam trabalhar juntas e compartilhar documentos, muitas das vezes elas estão espalhadas por setores ou até mesmo por regiões, onde a informação é precípua para a tomada de decisão.

Turban e Volonino (2013, p. 452) apresentam o conceito de:

Computação verde: Estudo e prática de recursos computacionais que são verdes (ecol-friendly); atualmente é uma preocupação chave dos negócios em todos os setores, não apenas em organizações envolvidas com o meio ambiente. [...] Iniciativa de conservar recursos naturais valiosos por meio da redução dos efeitos que o uso de computadores tem sobre o meio ambiente.

Os autores ressaltam a notabilidade de salvaguardar os recursos naturais e o uso eficiente de recursos computacionais, para que haja uma harmonia entre a tecnologia e o meio ambiente.

Ampliando o conhecimento, Oliveira, Perez Jr. e Silva (2002, p. 74) asseveram que:

A migração do sistema tradicional do uso intensivo de papeis e documentos comprobatórios das transações comerciais para a troca eletrônica de documentos fornece inúmeras oportunidades para tornar mais eficiente as operações rotineiras.

Sendo assim, nota-se que a Digitalização proporciona informação eletrônica, onde os documentos poderão ser administrados com maior facilidade, menor tempo e eficientemente. A demanda por informações mais elaboradas, cruciais e em tempo hábil são exigências cada vez mais requisitadas pelos Stakeholders. 
Para compreender melhor a digitalização Pereira (2012) expõe: a digitalização é o caminho do papel para o computador, é a transmissão de alguma coisa de um meio físico para o meio eletrônico. Ela é requisito para a existência da informação em um ambiente virtual.

\section{CONCLUSÃO}

Com o uso da tecnologia os documentos poderão ser melhores administrados levando a eficiência no processo de informação. E esta vem substituindo vários processos manuais, o que causa um impacto positivo nas empresas.

A presente pesquisa analisou a ferramenta de digitalização de documentos e os benefícios que a mesma apresenta. E conforme o estudo conclui-se que através da digitalização de documentos e do sistema de gerenciamento de informação tem-se uma maior rapidez e eficiência na tomada de decisões organizacionais. Os autores citados demonstram a verdadeira necessidade de aprimorar os processos através da digitalização como ferramenta gerencial que proporciona agilidade, fluidez, segurança, entre outros.

Ressaltou ainda, que a implementação da digitalização irá proporcionar uma redução dos impactos ambientais, questão de grande relevância nas empresas da atualidade.

Finalmente, espera-se que esta pesquisa traga uma contribuição para a empresa e para novos estudos acadêmicos. O tema é atual e relevante do ponto de vista organizacional, tanto na esfera pública quanto na privada e tem sido objeto de diversas linhas de pesquisa, por isso é de grande valia o aprofundamento deste estudo.

\section{REFERÊNCIAS}

AVEDON, D. M. GED de A a Z: tudo sobre Gerenciamento Eletrônico de Documentos. São Paulo: Cenadem, 1999.

JÚLIO, C. A.; SALIBE NETO, J. (orgs) Inovação e mudanças: autores e conceitos imprescindíveis. São Paulo: Publifolha, 2001.p.27-32. (Coletânia HSM Management)

LAUDON, K. C. LAUDON, J. P. Sistemas de Informação Gerencial. $7^{\circ}$ ed. São Paulo: Person Prentice Hall, 2007.

LUZ, E.E. Controladoria Corporativa. Curitiba: Ibpex, 2011.

MARCOVITCH, J. Crescimento econômico e distribuição de renda: prioridades para ação. São Paulo: Senac, 2007.

MORAES, G. Elementos do Sistema de Gestão de Smsqrs: Teoria da Vulnerabilidade. 2a ed. Rio de Janeiro: GVC, 2010. 
O' BRIEN, J. A. Sistemas de informação: e as decisões gerenciais na era da internet. 2. ed. São Paulo: Saraiva, 2004.

OLIVEIRA, D. P. R. Sistemas, organização e métodos: uma abordagem gerencial.

19. ed. São Paulo: Atlas, 2010.

OLIVEIRA, J. F. T.I.C.: Tecnologias da Informação e da Comunicação. São Paulo: Érica, 2003.

OLIVEIRA, L. M.; PEREZ JR., J. H.; SILVA, C. A. S. Controladoria Estratégica. São Paulo: Atlas, 2002.

OLIVEIRA, S. L. Tratado de metodologia científica: Projetos de pesquisas, TGI, TCC, Monografias, Dissertações e Teses. 2.ed. São Paulo: Pioneira, 1999.

PEREIRA, S.T. Processo eletrônico no novo CPC: é preciso virtualizar o virtual. Elementos para uma teoria geral do processo eletrônico. Jus Navigandi, Teresina, ano 17, n. 3172, 8 mar. 2012. Disponível em: <http://jus.com.br/artigos/21242>. Acesso em: 7 jul. 2014.

STAIR, R.M.; REYNOLDS G.W. Princípios de Sistema de Informação. 4o ed. Rio de Janeiro: LTC, 2002.

TURBAN, E.; VOLONINO, L. Tecnologia da informação para gestão: em busca do melhor desempenho estratégico e operacional. 8 ed. Porto Alegre: Bookman, 2013. 